\title{
The Impact of Ethnoscience Instruction on Cognitive Achievement in Science
}

\author{
Fasasi, Rasheed Adekunle (PhD) \\ Department of Teacher Education, \\ University of Ibadan. Nigeria \\ rafasasi@yahoo.com
}

\begin{abstract}
Prior cultural knowledge has been identified as a factor responsible for underachievement in science in traditional communities where differences exist between learners' everyday life and the world of science. Therefore, the purpose of this study was to investigate the main effect of Ethnoscience instruction and moderating effects of school location and parental educational status on students' cognitive achievement in science. It employed pretest-posttest, non-equivalent control group quasi-experimental design. Engaged in the study were 352 Junior Secondary School 1 students (aged 9-12 years) from two schools, each in urban and rural areas of İbàdàn, southwestern Nigeria. Instruments used are: Teachers Instructional Guide on Ethnoscience instruction, Teachers Instructional Guide on Modified Lecture Method and Basic Science Cognitive Achievement Test $(r=0.83)$. Three null hypotheses were tested at 0.05 level of significance. Data were analyzed using ANCOVA. Significant main effect of treatment was recorded on cognitive achievement in science [F(1,339) $=431.95 ; p<0.05]$ with Ethnoscience instruction group performing better than the control group. Effect size of treatment was strong $\left(\eta_{p}^{2}=0.63\right)$. Ethnoscience instruction is effective in promoting learners' cognitive achievement in science and is recommended as an instructional method for learners especially in traditional communities.
\end{abstract}

Keywords: Culture; ethnoscience instruction; cognitive achievement; parental educational status; school location

\section{Introduction}

Science, as positioned today, is the sine qua non for sustainable growth and development of a nation. The strength of a nation and the respect she commands from other nations are functions of her level of scientific and technological development. The increasing complexity of the world today imposes new and changing workforce requirements. This means that new workers will need ever more sophisticated skills in science, mathematics, engineering and technology which, in effect, require improved approaches to the teaching and learning of science. This explains why efforts are geared towards developing approaches that ensure the development of learners who would warm up to current workplace challenges. Consequently, Miles (2015) explains that academic success by science students requires that teachers implement a range of instructional strategies. This assertion informed the use of a number of innovative methods and strategies in the teaching and learning of science. For these methods and strategies to be effective, Bransford, Brown, Cocking, Donovan and Pellegrino (2000) highlight the importance of:

Received (June 15, 2017), Review Result (September 1, 2017), Accepted (September 11, 2017) 
a) using appropriate just-in-time learning stimuli;

b) engaging students' preconceptions prior to teaching them new concepts;

c) providing deep foundational knowledge;

d) helping students make appropriate connections within the context of a conceptual framework;

e) organizing knowledge in ways that facilitate information retrieval and application;

f) allowing students more opportunities to define learning goals and monitor their progress in achieving them.

While these innovative methods and strategies have been proved to have worked somewhere else, they do not seem to have been effective among science learners in traditional communities where differences exist between learners' everyday life and the world of science. A number of reasons have been adduced for this. Ogonnaya (2011), while analysing the situation in Nigeria affirms that the neglect of the diverse cultural activities and beliefs of the students and the failure of teachers to consider varied cultural resources of the students in teaching biology (and other sciences) remains one of the major reasons for the alienation of the students from sciences. Hiwatig (2008) narrows the reason for poor achievement in science to lack of regard for the cultural belief of learners which greatly influence the attitude. He, therefore, recommends the use of ethno-scientific teaching approach for classroom instruction in science. It is therefore important that an approach that is practical and relates science concepts to the day-to-day life of the learners be developed. To Cobern (1991), science as currently taught is a reflection of western history and foundational beliefs which makes it strange to learners in traditional communities in other parts of the world. These views are putting a question mark on the status of western science. This is perhaps why Absalom (2011) maintains that learners in the traditional non-western setting belief that science that is taught in schools often seems 'not their own' meaning that the concepts look strange in the traditional environment. Abonyi (1999) also notes that current instructional approaches in science education which did not take into consideration prior cultural beliefs seem to have contributed to poor concept formation and students interest in science.

In order to address the problem, a number of efforts have however been made. For example, Fafunwa, Macauley and Sokoya (1989) recommend the mother tongue approach based on the success of a programme in which students were taught science using Yorùbá, the local language. They are, however, criticized for transmitting western science concepts in local language (Abonyi, 1999). Achimugu (1995), in his own case recommends the use of improved local instructional materials. He is said to have succeeded only in improvising western instructional materials. The two recommendations have not removed the 'western' in them (Abonyi, 1999). Various conferences have also made failed attempts at integrating indigenous elements into science curriculum. These include conferences in Addis Ababa in 1961, Tanunarive in 1962, and Lagos in 1964 (Eshiet, 1991). There is therefore the need for a different approach to solving this identified problem. For such approach to be effective, it must meet some criteria as identified by George (2001) thus:

- $\quad$ access different ways of thinking about scientific concepts;

- $\quad$ bridge the gap between the traditional and the conventional.

This informs the need for an instructional method that is culturally responsive and students centred. Ethnosccience instruction has been identified as meeting these criteria (Abonyi, 1999). In justifying this, Fasasi (2017) defines ethnoscience instruction to mean the instructional approach that systematically accesses and assesses the prior cultural 
beliefs and ideas of learners that are related to the science concept being taught to ensure a better understanding of the concept.

School location has been a contentious issue in the determination of cognitive achievement in science education. Ndukwu (2002) maintains that schools located in urban areas are better positioned to attract more quality students and teachers who exhibit the readiness to take academic business seriously which will invariably impact on the students. Onah (2011) supports this empirically by finding out that schools in the urban areas achieved more than schools in the rural areas in science subjects. On the contrary, Bosede (2010) shows that school location has no effect on students' academic achievement in science. What is therefore the relationship between science students in urban and rural schools when ethnoscience instruction is used?

Parental educational status (PES) is a measure of the level of education of parents. It has been identified as an important factor affecting student achievement (Dryfoos, 1990). A number of studies have therefore been carried out to determine the impact of PES on learning outcomes. Sirin (2005) maintains that parent educational status is considered one of the most stable aspects of Socio-economic status (SES) because it is typically established at an early age and tends to remain the same over time. Research evidences show that learners with high-PES exhibit higher average levels of achievement than those with low-PES.

\section{Purpose of the Study}

The study investigated the effect of an Ethnoscience instruction on students' cognitive achievement in basic science. It also investigated the moderating effects of school location and parental educational status on the learning outcome.

\section{Hypotheses}

To guide this study, the following hypotheses were tested at 0.05 level of significance, the following null hypotheses were tested at 0.05 level of significance.

H1: There is no significant main effect of treatment on students' cognitive achievement in science.

H2: There is no significant main effect of school location on students' cognitive achievement in science.

H3: There is no significant main effect of parental educational status on students' cognitive achievement in science.

\section{Method}

\subsection{Research Design}

The study adopted a pretest-posttest, control group quasi-experimental design.

\subsection{Population and Sampling Technique}

The target population of the study consisted of all Junior Secondary I students in Ibadan Municipality (urban and rural centres) made up of 11 local government areas (5 in urban and 6 in rural areas). Stratified random sampling was used to select four public coeducational junior secondary schools that were used. Two schools were randomly selected from one randomly selected local government in the urban centre of the city while two schools were also randomly selected from one randomly selected local government in the rural centre of Ibadan. Two randomly selected intact classes were used in each school. 
This was to prevent the disruption of normal class activities noting that none of the classes had less than 90\% students with Yorùbá cultural background. The non-Yoruba students lived and daily interacted with members of the local community and were more likely to be influenced by the society. A total of 352 JS1students participated in this phase of the study.

\subsection{Instrumentation}

The instrument for data collection is Basic Science Cognitive Achievement Test (BSCAT). This was used in measuring the cognitive achievement of the students in science. It is made up of two sections. Section A was used to collect the subjects' personal data. Section B is a 40-item multiple choice test with four options (A-D), one of which is the correct option. All the questions were answered in one hour. The items were generated around three levels of cognitive domain i.e., Remembering, Understanding and Thinking in accordance with the recommendation of Okpala and Onocha (1995). The items were carefully selected to cover contents chosen from the four basic themes of the junior secondary basic science curriculum, namely You and Environment (Environmental conservation and Safety), Living and Non-Living Organisms (Matter and characteristics of Living and Non- Living Things), You and Science (Gravitation and Weightlessness), and You and Energy (Forces). The instrument, which was developed by the researcher is drawn from an initial 70 item objective test (representative of the selected topics which was given to four experts in the field of basic science and test construction to establish content and face validity. They were asked to ascertain the suitability of the items and their appropriateness for the target population and language clarity. Based on their advice, 10 (ten) items were dropped. Some others were modified for clarity.

The remaining items (60) were then administered on a sample of 35 Junior Secondary I (JSS I) Basic Science students in a school similar to those used for the treatment. An item analysis was performed to determine the difficulty levels and discrimination indices of the test items. Items that fell between the discriminating indices $0.40-0.60$ were selected indicating that the items were neither too simple nor too difficult. This reduced the items to 51. Forty (40) items were thereafter selected for proportional representation. The reliability co-efficient of the items was calculated to be 0.83 using Kuder-Richardson formula (KR 21). The total obtainable score is 40 marks with each question earning a mark.

Teachers instructional guides on ethnoscience instruction and teachers instructional guide on modified lecture were also used by the teachers involved in the study. Teachers instructional guides on ethnoscience instruction package was developed by the researcher and used for the treatment group while the teachers instructional guide on modified lecture package was drawn from the basic science curriculum module of the Federal Ministry of Education was used for the control group. They are identical in terms of contents, basic instructional objectives and mode of evaluation. The only differences are in the instructional activities and instructional materials in which Ethnoscience Instruction made use of additional previous information in respect of cultural beliefs, assertions and sayings that are related to the science concept being taught and learnt while also assessing and obtaining additional information from the learners. The learners were allowed to form their own opinion from the two expositions. They were also allowed to utilize additional instructional materials that reflected local beliefs. Ethnoscience instruction as enunciated by Fasasi (2017) involves the following broad steps:

(i) The teacher briefly introduces the concept to be taught and learnt;

(ii) The teacher enumerates and explains previously identified cultural beliefs, common sayings, and practices of the people of the locality that are related to the concept; 
(iii) Learners respond and are encouraged to list more related common sayings and other prior knowledge;

(iv) The teacher presents the new science concept and jointly with the students interact with relevant ethnoscientific instructional materials;

(v) Students compare new concept and related common Yorùbá sayings and classify the sayings into:

(a) Compatible;

(b) Modifiable; and

(c) Contradictory.

(vi) The teacher demonstrates and allows learners to interact with relevant other instructional materials;

(vii) The teacher asks questions, allows the students to ask questions, and summarises the lesson; and

(viii) The teacher gives assignment.

\subsection{Instrument Administration}

At the beginning of the experiment, BSCAT was administered as a pretest on subjects in both treatment and control groups. This was then followed by nine weeks of classroom interaction during which the regular basic science teachers of the schools taught the selected concepts by adhering strictly to the lesson procedure developed for each of the packages. The contents cover all the four broad themes of Basic Science curriculum. These are: You and Environment, Living and Non-Living Organisms, You and Science, and You and Energy.

The interaction was carried out during the normal school periods allocated on the school time table. At the end of the experiment, BSCAT was re-administered to the two groups as posttest and results from the two administrations (pretest and posttest) were used for data analysis.

\section{Data Analysis}

The study adopted the use of both descriptive and inferential statistics for analyzing the data gathered. Analysis of covariance (ANCOVA) was used to test the hypotheses and differences between the groups using the pretest scores as covariates. Estimated marginal means was used to identify where such differences occurred and determined the performance of each group.

\subsection{Results}

\subsection{Hyphotheses}

6.1. H1: There is no significant main effect of treatment on students' cognitive achievement in science. 


\section{Table 1. Summary of Analysis of Covariance (ANCOVA) of Students' Posttest Achievement Scores by Treatment, Location and Parent Educational Status (PES)}

\begin{tabular}{|c|c|c|c|c|c|c|}
\hline $\begin{array}{l}\text { Source of } \\
\text { Variation }\end{array}$ & $\begin{array}{l}\text { Sum of } \\
\text { Squares }\end{array}$ & df & $\begin{array}{l}\text { Mean } \\
\text { Square }\end{array}$ & $F$ & Sig. & $\begin{array}{l}\text { Partial Eta } \\
\text { Squared }\end{array}$ \\
\hline Corrected Model & $8127.77^{\mathrm{a}}$ & 5 & 1625.55 & 255.64 & .000 & .79 \\
\hline Intercept & 3641.01 & 1 & 3641.01 & 572.60 & .000 & .62 \\
\hline Pre achievement & 3117.97 & 1 & 3117.97 & 490.34 & .000 & .57 \\
\hline Treatment & 3717.05 & 1 & 3717.05 & 584.56 & $.000 *$ & .63 \\
\hline Location & 16.53 & 1 & 16.53 & 2.60 & .108 & .01 \\
\hline $\begin{array}{l}\text { Parent } \\
\text { Educational } \\
\text { Status }\end{array}$ & 11.10 & 2 & 5.55 & .87 & .419 & .01 \\
\hline Error & 2200.13 & 346 & 6.36 & & & \\
\hline Total & 172782.00 & 352 & & & & \\
\hline Corrected Total & 10327.90 & 351 & & & & \\
\hline \multicolumn{7}{|c|}{ a. $\mathrm{R}$ Squared $=.787($ Adjusted R Squared $=.784)$} \\
\hline
\end{tabular}

Table 1 reveals that there is a significant main effect of treatment on students' cognitive achievement in science $(F 1,346=584.56, p<0.05)$. This means that students exposed to treatment differ significantly in their post-test mean scores. Hence, hypothesis 1 is not supported. The size effect of treatment is moderate with partial eta squared being 0.63 , which means that $63 \%$ of the variance in scores is accounted for by treatment. To find out the group with higher adjusted mean score, the estimated marginal mean table (Table 2) of posttest achievement scores with the graph (Figure 1) is presented as follows:

\section{Table 2. Estimated Marginal Mean of Post Achievement Score}

\begin{tabular}{|c|c|c|c|c|}
\hline \multicolumn{5}{|c|}{ Dependent Variable: post achievement } \\
\hline & \multirow[b]{2}{*}{ Mean } & \multirow[b]{2}{*}{ Std. Error } & \multicolumn{2}{|c|}{ 95\% Confidence Interval } \\
\hline & & & Lower Bound & Upper Bound \\
\hline EI & $24.58^{\mathrm{a}}$ & .195 & 24.20 & 24.96 \\
\hline ML & $17.90^{\mathrm{a}}$ & .201 & 17.50 & 18.29 \\
\hline
\end{tabular}

Table 2 shows that learners in the ethnoscience instruction (EI) group had higher adjusted mean score $(\bar{X}=24.58)$ than the modified lecture (ML) group $(\bar{X}=17.90)$ in students' cognitive achievement in science. Table 1 shows that the difference in the adjusted mean scores is significant. The implication of this is that EI is a more effective method in improving learners' cognitive achievement.

6.2. H2: There is no significant main effect of school location on students' cognitive achievement in science.

Table 1 reveals that there is no significant main effect of school location on students' cognitive achievement in science $(F 1,346=2.60, p>0.05)$. This means that there is no significant difference in the cognitive achievement of urban and rural students in their posttest mean scores. Hence, hypothesis 2 is supported. 
6.3. H3: There is no significant main effect of parent educational status on students' cognitive achievement in science.

Table 1 reveals that there is no significant main effect of parent educational status on students cognitive achievement in science $(F 2,346=0.87, p>0.05)$. This means that there is no significant difference in students' cognitive achievement in science among students with low, average and high parent educational status in their posttest cognitive achievement in science scores. Hence, hypothesis 3 is supported.

\section{Discussion of Findings}

This study reveals that there was a significant main effect of ethnoscience instruction (EI) on cognitive achievement in science. The effect size is strong. A practical significance is also indicated. This means that ethnoscience instruction (EI) is a more effective method in improving learners' cognitive achievement than the modified lecture which served for control. This finding shows that EI assisted science learners in making sense of extant knowledge. It facilitated negotiation of meanings of science concepts since the method provides an opportunity for comparing what was known to new experiences and resolving discrepancies between what was known and what seemed to be implied by new experiences. These discrepancies have been very prominent in areas where science education has been influenced by common Yorùbá cultural beliefs and sayings. The result could also be explained by the link EI established between day-to-day experiences of the science learner and the world of modern science. The method derived strength from accessing prior common sayings of learners that are related to science which gave them the opportunity to re-examine the cultural meanings attached to the beliefs in terms of how realistic or logical they were. They had the opportunity to either hold on to the cultural meanings of the sayings, modify or reject them outright. Whichever was the case, it brought about improvement in the cognitive achievement of the learner. The result accentuates the need for integration of indigenous knowledge into school science in order to prevent a cultural clash whenever students attempt to learn meaningful school science. This will likely enable sustainable development and cultural survival. EI clearly facilitates the easiness with which students across cultural borders into school (western) science thus encouraging meaningful learning of science. This result should whet the enthusiasm of an increasing number of science educators who want to understand the cultural influence on school science achievement by students whose cultures and languages differ from the predominant eurocentric culture and language of science whether such students live in a non-western country like Nigeria, Russia or Malawi or they may live in a western countries like Britain, America, Canada etc. but are not at home with the culture of eurocentric science which permeates their school science classes. EI is equally an answer to scholars who wonder what role the integration of these knowledge systems will play in human life that the well-established three-century old science could not independently achieve (Sithole, 2005). Since science education does not occur in a vacuum, teaching and learning in science must be socially situated and this will impact positively on learning outcomes. This finding is in consonant with the thoughts of Ogawa (1995) in their writing on indigenous knowledge and science revisited.

The finding also supports Igbokwe (2010) who concludes that students who were taught using ethnoscience based cultural learning model performed better than those taught using the conventional method in cognitive achievement in science and concludes that since the cultural activities of each child as experienced from his cultural environment, guide or influence his future observation and also determine what is learned, for effective learning of science concepts to occur, the method should be adopted. It also confirms the assertion that it is the joint impact of what we teach and how we teach it that are important considerations in how to improve student success (Moore, Baum, and Glasgow, 1984). The finding also supports Hiwatig (2008) whose study compared 
ethnoscience class and the conventional class performances per item. It indicates that the ethnoscience class and the conventional class significantly differed in terms of their proficiency in the science posttest in four out of six items. The ethnoscience class had a higher mean score than the conventional class.

EI made it possible for learners to engage in critical comparison between the two knowledge systems. Such exercise develops the cognitive structure and understanding of the learner. It is a better approach that clearly removes the assumption or pretence that indigenous knowledge has nothing to offer in the teaching and learning of science. There is no doubt that psychological and sociological approaches are useful in education but the inclusion of the elements of indigenous knowledge in classroom activities through ethnoscience instruction has provided fresh insight into and solutions to problems associated with students learning science. This confirms earlier assertion of Cobern (1991) on the issue of cultural aspect of learning science. Since students also had the opportunity of interacting with related cultural materials as instructional materials, their understanding of science concepts improved. The impression of science being 'foreign' or "oyinbo' (whiteman) knowledge as usually said locally must have challenged their prior knowledge. They probably saw the science concept as no longer strange. The method also promoted discourse in science among learners since it gave them the opportunity to be actively involved in discussing both the science concept being learnt and the related common Yorùbá cultural beliefs and sayings. They were trekking a familiar path in the discussion rather than the teacher pouring down all the 'facts'.

Findings from this study reveal that there is no significant main effect of school location on students' cognitive achievement in science. This implication is that there is no difference in the cognitive achievement of urban and rural students with the use of ethnoscience instruction. It supports the work of Reeves (2005) whose results do not support the claim that rural students achieve less well than their non-rural peers in mathematics and science. Various reasons can be adduced for this. Despite the seeming disadvantaged position of students in rural schools in terms of infrastructure, they still marched students from the urban centre in terms of cognitive achievement. EI removed the strangeness in science concepts and appealed to them in the language they understood. They felt science through the link the method used established with their day to day life activities and expressions. Students in rural schools are believed to be closer to culture than those in urban schools. Their expressions and beliefs show greater attachment to culture. It is therefore not surprising to find them better motivated in learning science when the method of instruction used is culturally appealing. Some of the instructional materials used under EI are more often used by students in rural areas. For instance catapult is common tool used in hunting expeditions by students in rural areas. They use it in killing birds, lizards and so on. While the sight of catapult is not strange in urban centre, it is of limited use as children are warned against its use since it could lead to the breakage of vehicle windscreens, glass windows and other breakable materials apart from causing physical injuries to man.

Lastly, the study also reveals that there is no significant main effect of parent educational status on students' cognitive achievement in science. This implies that there is no significant difference in cognitive achievement in science by learners with low, average and high parent educational statuses. One major reason for this could be the fact that most parents (fathers and mothers) of all categories in term of educational attainment now spend so much time running after means of sustenance that they no longer have time for their children's educational achievement. This is especially the case with parents of learners in public schools who invest little in the educational development of their children confirming the local saying that 'oogun ti a fi owo se, eyin aaro lo ngbe' meaning drug freely given easily goes unused. This finding supports Ojedokun (2006) that parent educational status does not significantly influence vcognitive achievement but contradicts Ogwu (2006) who maintains that parent educational status is significantly and 
positively related to achievement. This is also the conclusion of Awofala (2010) who asserts that there is a significant main effect of parent education background on students' achievement in mathematics word problem. It reveals that students with parents having educational background performed better than their peers from low educational background.

\section{Conclusion}

This study was carried out as part of efforts by educators and researchers at identifying factors influencing cognitive achievement of learners. It also invested efforts on determining the effects of incorporating the knowledge of learners' cultural beliefs into classroom interaction. It helped to identify differences among students due to school location and parental educational status. It is also hoped that this work would engender the much desired improvement in cognitive achievement of science learners irrespective of cultural differences.

\section{Recommendations}

Based on the findings of this study, the following recommendations are made:

i. Educators, administrators and other stake holders in the education sector should be trained on the importance and use of ethnoscience instruction and encouraged to start using it for classroom instruction.

ii. There should be the incorporation of basic ethnoscientific materials into the national curriculum to effect the much desired improvement in learners' cognitive achievement in science.

iii. Efforts must be made in indigenising instructional materials used in teaching of science especially in communities that still have close affinity to their cultural beliefs.

iv. This study should be replicated among learners in traditional communities in various [parts of the world where cultural beliefs still guide their day-to-day activities.

\section{Contributions of this Paper to the Literature:}

- The study reveals the need for culture-related instruction in the teaching and learning of science concepts especially among learners in communities where day-to-day activities are still influenced by local tradition.

- The study also reveals that ethnoscience instruction is effective in improving learners' cognitive achievement.

- The study shows that using ethnoscience instruction, students' cognitive achievement is not influenced by school location and parent educational status.

\section{References}

[1] O. S. Abonyi, "Effects of an Ethnoscience- Based Instructional Package on Students' Conception of Scientific Phenomena and Interest in Science", Thesis. University of Nigeria. Nsukka, (1999).

[2] D. K. P. Absalom, "Exploring the Integration of Indigenous Science in the Primary School Science Curriculum in Malawi”, Thesis. Teaching and Learning. Virginia Polytechnic Institute and State University, (2008).

[3] L. Achimugu, "Effects of Selected Improvised Conventional Teaching Materials on Students Achievement in and Attitude Towards Chemistry", Thesis. Science Education, Education. University of Nigeria, (1995). 
[4] A. O. A. Awofala, "Impact of Personalised Instruction on Senior Secondary School Students' Learning Outcomes in Mathematics Word Problems", Thesis. Teacher, (2010).

[5] A. F. Bosede, "Influence of sex and location on relationship between students problems and academic performance", The social science, vol. 5, no. 4, (2010), pp. 340-345.

[6] J. D. Bransford, A. L. Brown, R. R. Cocking, M. S. Donovan and J. W. Pellegrino, "How People Learn: Brain, Mind, Experience, and School (Expanded ed.)", Washington, D.C.: National Academy Press, (2000).

[7] W. W. Cobern, "World view Theory and Conceptual change in science education", Monograph of National Association for Research in Science, (1991).

[8] J. G. Dryfoos, "Adolescents at risk”, NY: Oxford University Press, (1990), pp. 23.

[9] I. Eshiet, "Teaching Science, Mathematics and Technology in Mother Tongue. Philosophical Implications", 32nd Annual Conference Proceedings of Science Teachers Association of Nigeria, (1991), pp. 3-10.

[10] B. Fafunwa, J. I. Macauley and J. A. F. Sokoya, "Education in mother tongue: The IFE primary research project (1970-1978)", Ibadan: University Press, (1989).

[11] R. A. Fasasi, "Effects of Ethnoscience Instruction, School Location and Parental Educational Status on Learners Attitude Toward Science", International Journal of Science Education, DOI: 10.1080/09500693.2017.1296599, (2017).

[12] J. George, "Culture and Science Education. A look from the Developing World", An Action Bioscience, (2001). www.id21.org/education/e31g2'html. Retrieved, (2009) August 23.

[13] A. D. F. Hiwatig, "Ethno-Scientific Teaching Approach, Student Proficiency, and Attitude Toward Science and Ethnic Culture", Education Quarterly, vol. 66, no. 1, (2008) December 3-21.

[14] O. C. Igbokwe, "The Effect of Multicultural Learning Environment on Cognitive Achievement of Pupils in Primary Science", Journal of the Science, (2010).

[15] R. Miles, "Tutorial instruction in science education", Cypriot Journal of Educational Science, vol. 10, no. 2, (2015), pp. 168-179.

[16] E. J. Moore, E. L. Baum and R. B. Glasgow, "Economic factors influencing educational attainment and aspirations of farm youth", Washington, DC: Economic Research Service, Resource Development Division. (ERIC Document Reproduction Service Document No. ED 015797), (1984) April.

[17] U. P. Ogonnaya, "Fostering the Understanding of Biological science concepts at the Senior Secondary School level using Collateral learning Strategy" Journal of Science Teachers Association of Nigeria, vol. 52, (2011), pp. 242-247.

[18] S. Ogwu, "Influence of Parental SES on Academic Performance of JSS students in Kano metropolis: Implication for educational planning and administration", Project. Bayero University, Kano, (2006).

[19] O. E. Ojedokun, "Effects of Concept-Intergration and Two Life-Skill Methods on Secondary Schools Students Knowledge of, Attitude to, and Risk-Practices Related to HIV/AIDS", Thesis. Teacher Education, University of Ibadan, (2006).

[20] P. N. Okpala and C. O. Onocha, "Difficulties in Students Performance of Hierarchal Cognitive Tasks", A function of Time to Learn" UNESCO Africa. (A Six Monthly Journal of the Dakar UNESCO Regional Office, (1995).

[21] E. F. Onah, "Influence of sex and school location on students' achievement in agricultural science", African journal of science, Technology and Mathematics Education (AJSTME), vol. 1, no. 1, (2011), pp 96-102.

[22] P. N. Ndukwu, "School and teacher factors material resources utilization in pre-primary schools in Lagos State", Unpublished Ph.D Thesis, University of Ibadan, Ibadan, (2002).

[23] E. B. Reeves, "The Effects of School Location on Math and Science Achievement Trends: A Primer on Growth Modeling in Education Policy Research", Paper presented at the 12th Annual International Learning Conference held at the University of Granada, Granada, Spain. July. Occasional Research Paper, No. 11. Morehead State University, (2005).

[24] S. R. Sirin, "Socioeconomic status and academic achievement: A meta-analytic review of research", Review of Educational Research, vol. 75, no. 3, (2005), pp. 417-453.

[25] M. P. Sithole, "Science versus indigenous knowledge: A conceptual accident", Ingede: Journal of African Scholarship, vol. 1, no. 1, (2005), pp. 1-5.

\section{Author}

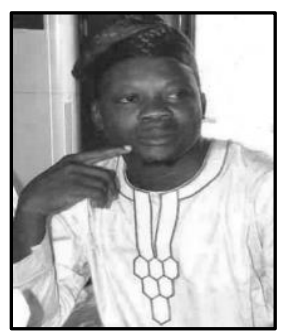

Dr. Rasheed Adekunle Fasasi obtained his $\mathrm{PhD}$ in Science Education from the University of Ibadan. A major area of his research focus is on science and culture. $\mathrm{He}$ is an educational consultant and a teacher. $\mathrm{He}$ is an adjunct lecturer with the National Open University of Nigeria. He is also interested is Agricultural education and Environmental studies in his research work. 